\title{
Solid-state solubilities of grain -growth inhibitors in WC-Co and WC-MC-Co hardmetals
}

\author{
Lauter Lukas ${ }^{1}$, Hochenauer Roman ${ }^{1}$, Buchegger Christoph ${ }^{1}$, Bohn Marcel ${ }^{2}$, Lengauer Walter 1, *
}

1 Vienna Univ Technol, Getreidemarkt 9-164CT, A-1060 Vienna, Austria.

2 IFREMER, CNRS, F-29286 Plouzane, France.

* Corresponding author : Walter Lengauer, email address : walter.lengauer@tuwien.ac.at

\begin{abstract}
:
The solubilities of the most common grain -growth inhibitors (GGls) $\mathrm{Cr}, \mathrm{V}, \mathrm{Ta}, \mathrm{Mo}, \mathrm{Nb}, \mathrm{Zr}$ and certain combinations there of in the binder phase of WC-Co hardmetals as well as hardmetals of the type WCTiCTiN-TaC-NbC-Co containing an fcc MC carbide (or carbonitride) phase "MC"("WC-MC-Co" hardmetals) were analysed by means of WDS-EPMA. The carbon potential of the binder phase was fixed at its highest and lowest maxima by the presence of either graphite or eta (M6C) phases. In case of low-carbon hardmetals the composition of M6C, and in the MC-containing hardmetals the composition of the MC phase, was analysed. Two types of solubilities were determined. The first type was measured after controlled cool-down from liquid-phase sintering temperature and represented the binder phase state of an industrially prepared hardmetal. The second type representing the equilibrium solubility was measured in alloys annealed at 1000 degrees $\mathrm{C}$ for $168 \mathrm{~h}$ after liquid -phase sintering. The measured solubilities were subsequently used to prepare hardmetals with an optimised GGI concentration. The samples were analysed with respect to hardness, toughness, magnetic properties, transverse rupture strength and Weibull parameter. A complex doping with $\mathrm{Cr}, \mathrm{V}$ and $\mathrm{Ta}$ with optimised concentrations near the solubility limit of these metals in the binder phase turned out to yield best combination of mechanical properties and reliability. This was successfully adopted in industrial production.
\end{abstract}

\section{Highlights}

- The most complete study of solid-state solubilities of grain-growth inhibiting metals so far. Optimisation of solubilities for enhancement of hardmetal properties. Optimised hardmetal properties (TRS and Weibull parameter $\mathrm{m}$ ) successfully implemented in industry.

Keywords : Hardmetal, Cemented carbides, Grain-growth inhibitor, Nitrogen, Binder phase, Solubility, EPMA 


\section{Introduction}

Ultrafine-grained hardmetals with a mean WC grain size below $0.5 \mu \mathrm{m}$ were developed in the recent decades and are nowadays indispensable for a broad range of industrial key applications [1]. Due to the high driving force for grain coarsening such low grain sizes are only accessible by the application of grain-growth inhibitors (GGls) [2, 3]. Especially in ultrafine and near-nano grades the grain growth already initiates at relatively low temperatures. Suitable dopants hence influence the microstructural evolution already in solid state [4,5]. Meeting these requirements, the application of GGls is well established in the industrial manufacturing process today. Vanadium was found to be the most effective inhibitor [6], chromium, tantalum, molybdenum, niobium and titanium are as well applied in varying combinations, besides growth inhibition also with respect to the adjustment of specific material parameters. Their inhibition efficiency increases with rising concentration. However, once the temperaturedependent solubility limit in the binder phase is exceeded, free GGI-based carbide phases form (e.g. VC, $\mathrm{Cr}_{3} \mathrm{C}_{2}, .$. ). Vanadium [7-14] and chromium [15] were reported to form thin layers at the WC/binder interface. Especially for vanadium it seems confirmed that such GGI-based layers of a few atomic layers thickness exist in equilibrium state even if the vanadium concentration is below the solubility in the binder phase. If the inhibitor concentration exceeds the solubility limit brittle, GGI-based carbides precipitate, with possible negative consequences on mechanical properties [16], especially in case of chromium and vanadium. Recent developments in thermodynamic and kinetic simulations pushed the determination of liquidphase solubilities in order to gain input data for calculations. However, for hardmetal production the solid-state solubility is of greater interest. Surprisingly, only restricted data is available on the solubility of dopants [17-20] and the general binder-phase composition [21-25] in solid state. The dopant concentrations applied in industrial production are mostly empirically determined in order to maximise the GGI concentration and avoid free GGI-based carbide precipitation. If the GGI concentration only slightly exceeds the solubility small precipitates will form e.g. at the interfaces which are not detectable by commonly used imaging methods such as SEM/BSE or LOM. The present work hence aims to answer the solid-state solubility of the most common GGls V, Cr, Mo, Ta and $\mathrm{Nb}$ and combinations thereof in the binder phase of a WC-Co-GGI hardmetal in an oversaturated state after (1) a cool-down from the sintering temperature and (2) an equilibrium state at $1000^{\circ} \mathrm{C}$. In hardmetals with low carbon potential matching the equilibrium $\mathrm{WC}_{+} \mathrm{M}_{6} \mathrm{C}+\mathrm{MC}+$ binder $\mathrm{GGls}$ are not only dissolved in the binder phase but have certain solubility in the $\mathrm{M}_{6} \mathrm{C}$ phase. Some authors published experimental or calculated data on the solubility of $\mathrm{V}$ and $\mathrm{Cr}$ in the $\mathrm{M}_{6} \mathrm{C}$ phase [18-19]. For vanadium a solubility of $5-6$ at\% was reported at $1200^{\circ} \mathrm{C}$ [19], compare Tab. 1 .

\section{Methodological approach}

The idea behind this work is to gain solubilities of a number of popular grain-growth inhibitors (GGIs) and combinations thereof in the binder phase of WC-Co hardmetals. In such alloys the appearing phases have the principal composition of a hardmetal but a significantly increased binder volume fraction. All elements such as W, C and varying combinations of the GGIs $\mathrm{Cr}$, $\mathrm{V}, \mathrm{Mo}, \mathrm{Nb}, \mathrm{Ta}$ and $\mathrm{Zr}$ are added in excess in order to create a binder phase saturated with these elements. The solubility of most of them depends on the carbon potential. Within the WC-Co system the carbon potential and, hence, the binder phase composition is fixed when either eta-phase $\left(\mathrm{M}_{6} \mathrm{C}\right)$ or graphite precipitations appear [26]. The composition within the $\mathrm{WC}+\mathrm{MC}$ two-phase area changes as a function of carbon potential but remains between the 
borders defined by the presence of eta-phase and graphite. In this work it is assumed that this behaviour is also valid in presence of GGls, i.e. thermodynamic calculations have shown, that the invariant three-phase equilibria in a WC-binder system is no more invariant, if a further phase is added (Gibbs' phase rule), but the temperature variation with changing $C$ content is on the order of around $1^{\circ} \mathrm{C}$ in the vicinity of the WC+Co phase field, (compare e.g. [27]). Hence, the model alloys are composed of WC, Co binder phase, and free GGI-based carbides formed by abundant GGls aa well as either eta-phase or graphite to fix the minimal or maximal carbon potential, respectively.

The microstructure of such model alloys is defined by the high binder volume fraction of 50 $60 \mathrm{vol} \%$, which yields large binder areas of several $\mu \mathrm{m}$ in diameter without any precipitates. These binder areas are accessible to electron-probe microanalysis (EPMA) which has a lateral resolution of $1-3 \mu \mathrm{m}$. It is essential that the sample is in equilibrium state prior to the analysis. This precondition can be checked by performing line scans within the binder phase of a model alloy. Such scans do not show any concentration gradients if the sample is sufficiently equilibrated. The method is capable of simultaneous, quantitative multi-element analysis, a detailed description and applications to hard phases and hardmetals is given elsewhere [2830].

\section{Experimental}

\subsection{Sample preparation}

Two different series of model alloys with an increased cobalt content of $50 \mathrm{wt} \%$ were prepared. The first series "M" is based on the formula WC-GGI-binder and aims to determine the GGI solubility in WC-Co hardmetals. The composition of the M series is listed in Tab. 2. The second series "MC" is based on the principal formulation WC-TiC-(TiN)-TaC-NbC-binder and aims to gain solubilities of chromium and vanadium in MC-phase-containing hardmetals. The MC samples were prepared without TiN, whereas MC_N1 contained 1 wt $\%$ TiN and MC_N2 2 wt\% TiN. The initial composition of the MC series is listed in Tab. 3. The powder grades used for preparation were Co (Umicore, extrafine, FSSS $=1.3 \mu \mathrm{m})$, WC $(\mathrm{H} . \mathrm{C}$. Starck DS80, FSSS $=0.8$ $\mu \mathrm{m}), \mathrm{W}($ H.C. Starck HC $70 \mathrm{~S}$, FSSS $=0.62 \mu \mathrm{m})$, carbon black (H.C. Starck Luvocarb, $\mathrm{BET}=10.6 \mathrm{~m}^{2} / \mathrm{g}$ ), $\quad \mathrm{Cr}_{3} \mathrm{C}_{2} \quad$ (Treibacher, fine, FSSS=1.7 $\left.\mu \mathrm{m}\right), \quad \mathrm{Mo}_{2} \mathrm{C}$ (Treibacher, fine, FSSS $=1.6 \mu \mathrm{m}$ ), NbC (Treibacher, NbC100-standard, FSSS=1.3 $\mathrm{m}$ ), TaC (Treibacher, TaC100-fine, FSSS $=0.9 \mu \mathrm{m}$ ), VC (Treibacher, fine, FSSS $=1.1 \mu \mathrm{m}$ ) and ZrC (Treibacher, FSSS $=1.6 \mu \mathrm{m})$. The impurity content of these powders meets the standards of hardmetal production and was below $0.01 \mathrm{wt} \%$ for any metal impurity. The oxygen content, which is generally below $0.3 \mathrm{wt} \%$, that of $\mathrm{Cr}_{3} \mathrm{C}_{2}$ below $0.6 \%$, is reduced within sintering by $\mathrm{CO}$ evolution [31]. Hence, the alloys are practically free of oxygen.

For model alloys powders were dry-mixed in a "Turbula" shaker using hardmetal milling balls. The $\mathrm{M}$ series model alloys were liquid-phase sintered in a corundum crucible at $1400^{\circ} \mathrm{C}$ for $60 \mathrm{~min}$ in $100 \mathrm{mbar}$ argon atmosphere using induction furnace equipment. After cool-down samples were cut in two pieces. One peace was not further treated in order to determine solubilities after cool-down. The other piece was put in Mo foil and encapsuled in a fused silica tube in argon atmosphere and annealed at $1000^{\circ} \mathrm{C}$ for $168 \mathrm{~h}$ in order to equilibrate the binder phase. Both the equilibrated and non-equilibrated samples were metallographically processed. MC model alloys were liquid-phase sintered at $1440^{\circ} \mathrm{C}$ for $30 \mathrm{~min}$. Two different atmospheres were applied. The first type was vacuum until $1100^{\circ} \mathrm{C}$ and subsequently 300 mbar argon. The atmosphere of the second type was vacuum until $1100^{\circ} \mathrm{C}, 50$ mbar nitrogen until $1440^{\circ} \mathrm{C}$ and 
25 mbar nitrogen at sintering plateau. After controlled cool-down with $10 \mathrm{~K} / \mathrm{min}$ the samples were wrapped in Mo foil, sealed in fused silica tubes in argon atmosphere and annealed at $1000^{\circ} \mathrm{C}$ for $168 \mathrm{~h}$.

The solubilities determined from $M$ series in the cooled, non-equilibrated state were subsequently applied to hardmetals with optimised GGI content. Optimised refers to maximisation of the GGI concentration in the binder phase but avoiding GGI-based carbide precipitations. The compositions (Tab. 4) were calculated based on the non-equilibrium solubilities since they are representative for industrially sintered hardmetals. The carbon potential was adjusted by $\mathrm{C}$ and $\mathrm{W}$ addition (as commonly performed in industry) to arrive in the WC+binder two-phase area and that the relative magnetic saturation of $79-81 \%$ was achieved for one group of hardmetals and $91-93 \%$ for the other. Since the GGI solubility depends on the particular carbon potential the mean value of the solubility at fixed high and low potential as listed in Tab. 5 was used for calculating of the optimised hardmetal formulation. The hardmetal powder mixtures were wet milled in cyclohexane using hardmetal linings and uniaxially pressed to rods. The rods were sintered at $1390^{\circ} \mathrm{C}$ for $60 \mathrm{~min}$ in vacuum and subsequently HIPed with 93 bar argon. The sintered rods had a length of $38 \mathrm{~mm}$ length and $2.81 \mathrm{~mm}$ in diameter with a surface roughness of $\mathrm{Ra}<0.4$.

\subsection{Sample analysis}

Light-optical microscopy (LOM) and X-ray diffraction (XRD) were used in order to check on the presence of the intended phases such as WC, fcc hard phases, fcc binder, GGl-based carbides and graphite or $M_{6} C$. Since XRD was capable of identifying only major phase amounts such as WC and Co and occasionally eta-phases, the identification of minor amounts of phases in the model alloys was performed by successive addition of GGI phases and inspection of the increasing amounts of phases in the LOM. For this purpose, the etching attack on the various phases was inspected. Generally, Murakami solution was applied and the different etching behaviour was used for phase identification.

The composition of the particular phases was analysed by wavelength-dispersive electronprobe microanalysis (WDS-EPMA) using a Cameca SX100 microprobe equipped with five spectrometers. The measurement of peak position was usually $10 \mathrm{~s}$, that of the background position $5 \mathrm{~s}$. Pure cobalt metal, and carbides in case of other elements, were used as calibration standards. The preparation and characterisation of the standards is described elsewhere [29]. 3-5 line scans in 2-3 different binder areas with a total of about 100 particular data points were analysed for each sample in order to achieve statistically significant values. In order to record any influence of fine precipitates, as well as phases or pores below the surface, which cannot be identified but could be located within the analytical volume, the non-normalised analytical total - which is the sum of all elements and not normalised, e.g. to $100 \mathrm{wt} \%$ - was recorded [29]. This analytical total was only accepted if it was located between 99-101wt\% together with the fact that the recorded compositions was constant without any sign of deviation and discontinuities within the sections of a line scan [28]. Such a procedure gives an unambiguous sign of any inhomogeneity in the analytical volume.

Three-point bending tests were conducted using Wolpert equipment. 20 single hardmetal rods for each particular hardmetal were tested, allowing the application of Weibull statistics. In addition, hardness HV30, fracture toughness (Palmqvist-Shetty) $\mathrm{K}_{\mathrm{lc}}$, porosity (ISO), magnetic saturation $4 \pi \sigma$ and coercive force $H_{c}$ were measured for further specification. 


\section{Results and Discussion}

\subsection{Solubilities of GGIs in the binder phase of WC-Co}

The microstructures of the model alloys composed according to Tab. 2 are illustrated by the Murakami-etched (5s) LOM micrographs in Fig. 1. All samples show the intended phase equilibria binder+WC+MC+eta or binder+WC+MC+graphite. The respective phases are indicated by coloured arrows. The composition of the GGl-based carbides was not further specified since the focus was on the solubility of GGls in the binder phase.

After cool-down from sintering temperature the binder phase is not equilibrated but oversaturated with alloying elements. The degree of oversaturation is influenced by the cooling rate where lower rates yield less oversaturation. The cooling rate applied in this work is $10 \mathrm{~K} / \mathrm{min}$ and hence in the range of common industrial conditions. Below $900-1000^{\circ} \mathrm{C}$ the diffusion of GGls is slow and the binder composition de facto frozen [32-34]. The composition of the binder phase at such conditions for various dopants is listed in Tab. 5. Substantial solubilities are measured for chromium (5.7-10.4 wt\%), molybdenum (4.8 wt\%) and vanadium (1.0-1.7 wt\%). For tantalum a measurable solubility was only found for low carbon potential (2.7 wt\%) whereas it is below the EPMA detection limit at high $\mathrm{C}$ potential. No considerable solubility was measured for $\mathrm{Zr}, \mathrm{Nb}$ and the combination thereof. In any case, the dissolution of GGls substantially decreases the tungsten content of the binder phase. In an almost GGI-free binder phase (e.g. $\mathrm{Zr}$ or $\mathrm{Nb}$ doped) the tungsten content is around $22-23 \mathrm{wt} \%$, at low $\mathrm{C}$ potential, but drops to $13 \mathrm{wt} \%$ in presence of chromium. Vanadium has a less distinct effect on the tungsten content (18 wt\%).

In the double-doped samples M_CrV the solubility of chromium is markedly reduced from 10.5 to $5.5 \mathrm{wt} \%$ at low carbon potential. The vanadium concentration drops as well from 1.7 to $1.0 \mathrm{wt} \%$. This effect is far less distinct at high carbon potential.

It is a general trend that the solubility of GGls is higher at low carbon potential. Interestingly, the molybdenum concentration does not meet this finding but remains independent from the carbon potential.

Although the binder-phase compositions in the as-cooled state are relevant for hardmetal industry, they are insufficient as input for thermodynamic modelling. Such methods require equilibrium data, which was determined from the model alloys annealed for $168 \mathrm{~h}$ at $1000^{\circ} \mathrm{C}$. The results of these experiments are listed in Tab. 6. The findings are similar to those discussed above. The measured solubilities are generally slightly lower (by $0.1-0.7 \mathrm{wt} \%$ ) as compared to the non-equilibrated state. The strongest effect of the annealing process was found for tungsten (up to $5 \mathrm{wt} \%$ reduction). However, this observation is mostly explained by the higher molar mass of tungsten, the reduction in terms of atomic ratio is in the range of GGIs. Contrary to the general trend, the solubility of vanadium increased by $0.1-0.6 \mathrm{wt} \%$. This increase might be possible due to the reduction of the $\mathrm{W}$ concentration but the reason cannot be clarified by the methods used in this work.

Additionally to the binder phase also the eta-phase of assorted low-carbon alloys was analysed. The results are shown in Tab.7. It should be kept in mind that the carbon analysis in such a low concentration range is only semi-quantitative. Due to a chemical shift of the carbon emission line in EPMA analysis eta-phase standards would be required to enhance carbon analysis. However, it can be seen that all investigated formulations show certain GGI solubility, though it is low for tantalum and around the detection limit for niobium. Based on the principal formulation $\mathrm{Co}_{3} \mathrm{~W}_{3} \mathrm{C}$ the GGls replace up to $30 \%$ of the tungsten atoms, while no cobalt seems to be replaced. 


\subsection{Solubility of GGIs in the binder phase of WC-TiC-TiN-TaC-NbC-Co}

The microstructures of the MC samples are illustrated in Fig. 2. The micrographs of all samples indicate the intended phase composition. It is particularly striking that the vanadium-containing samples with high carbon potential in nitrogen atmosphere (MC_N1_V and MC_N2_V) from a fine network of needle-like WC crystals. All samples have large free binder areas suitable for EPMA analysis. The solubilities of $\mathrm{Cr}, \mathrm{V}$ and $\mathrm{W}$ in the binder phase of MC-containing hardmetals are listed in Tab. 8. The concentrations for $\mathrm{Ta}, \mathrm{Ti}$ and $\mathrm{Nb}$ are not listed since their values were below the detection limit for all analysed samples. The measured GGI solubilities are generally lower as compared to the $\mathrm{Cr}+\mathrm{Ta}$ or $\mathrm{V}+\mathrm{Ta}$ doped $\mathrm{M}$-series grades. In case of chromium-doped samples the effect is significantly more distinct at low carbon potential (3040 rel\%) than at high potential (0-10 rel\%). In vanadium doped samples a solubility reduction of $\sim 50$ rel\% was found in presence of fcc hard phases, independent from the carbon potential. No significant influence of nitrogen was measured in GGI-doped as well as undoped samples. The solubilities are equal within the error range and hence independent from nitrogen atmosphere or the presence of nitrides.

The composition of the fcc hard phase is listed in Tab. 9. It can be seen that especially the vanadium concentration increases significantly from 1.5 at $\%$ to $5-6$ at $\%$ in presence of nitrogen. However, the chromium solubility is lower around 2 at $\%$ and independent from the presence of nitrogen.

\subsection{Hardmetals}

Based on the solubilities determined from model alloys hardmetals with a corresponding GGI content were prepared. Fig. 3 shows the SEM microstructure of a $\mathrm{Cr}+\mathrm{V}+\mathrm{Ta}$ triple doped WCCo hardmetal. The achieved mechanical properties are listed in Tab. 10. Any double- and triple-doping combinations yield comparable values with respect to hardness vs. toughness and are superior to single-doped grades. The latter is most likely related to an enhanced graingrowth-inhibiting effect. Hardness and toughness are commonly used to specify hardmetals. However, these values are not sufficient for optimising hardmetals, since they allow no conclusions on the effect of material defects or specific features of the binder phase. Such information is accessible by bending tests. Two parameters can be determined from such tests. The first one is the transverse rupture strength (TRS), which yields information on material strength. The second one is the Weibull parameter $\mathrm{m}$, providing information on the reliability of the material. The hardmetals prepared in this work were HIPed in order to eliminate effects of porosity on TRS and $\mathrm{m}$. As described elsewhere [28] a high $\mathrm{C}$ potential in hardmetals yields lower TRS values than a low $C$ potential. This is because a high $C$ potential causes the formation of larger WC grains which reduce TRS.

The results of the bending tests of the low-C-potential hardmetals are illustrated by means of a Weibull plot in Fig. 4. Data points represent particular samples out of a series of 20. The straight line is a linear fit to these data points. The slope of this fit is defined as $\mathrm{m}$, while the bending strength at $50 \%$ fracture probability marks the TRS.

Single-doped hardmetals yield lower TRS values as compared to complex-doped grades. Double-doped hardmetals yield a comparable three-point bending behaviour with similar TRS and Weibull parameter. $\mathrm{Cr}+\mathrm{V}+\mathrm{Ta}$ triple doping also yields a TRS of 4.7 GPa which is equal to double-doped grades. However, with a Weibull parameter of $m=59$ it is superior to all other grades. The advanced properties of triple-doped hardmetals were as well found for ultrafine hardmetal grades [35]. Hardmetals with industrially common $\mathrm{Cr}+\mathrm{V}$ or $\mathrm{V}+\mathrm{Ta}$ doping are hence 
sufficient with respect to hardness and toughness, but can be further improved with respect to their reliability by adding tantalum. The observed effects are a convolution of the GGI impact on the carbide skeleton by growth control and on the modification of the binder phase chemistry. The single contributions cannot be distinguished by the methods used in this work. However, it was shown that hardmetal can still be optimised by choosing optimised GGI combinations.

\section{Conclusion}

This work provides information on the solubility of a wide range of grain-growth inhibitors (GGls) such as $\mathrm{Cr}$, V, Ta Mo, Nb and $\mathrm{Zr}$ and combinations thereof in the binder phase of WCCo hardmetals. Model alloys with the principal phase composition of a hardmetal but an increased binder content were prepared, in order to make the binder phase accessible to EPMA analysis. The carbon potential of the alloy was fixed at its maximum and minimum value by the presence of graphite or eta-phase, respectively. Two types of solubilities were determined. The GGI solubility in the binder phase after a cool-down allows insight into the binder composition after an industrial sintering process. The solubility after $168 \mathrm{~h}$ equilibration at $1000^{\circ} \mathrm{C}$ and a following rapid quench delivers valuable input for thermodynamic simulations. The analysis of the eta-phase in doped low-carbon alloys revealed that up to $30 \%$ of tungsten atoms can be replaced by GGIs.

Considering the measured solubilities hardmetals with optimised binder composition and relative magnetic saturation of around $80 \%$ were prepared. Such hardmetals had a binder phase with maximum possible GGI concentration but avoided the presence of GGI-based carbides, as observed by SEM and also indicated by the high TRS values. By a combination of hardness, fracture toughness and three-point bending tests it was demonstrated that proper combination of GGls such as $\mathrm{Cr}, \mathrm{V}$ and $\mathrm{Ta}$ at their solubility limit can significantly enhance both the mechanical properties and the reliability of a hardmetal. The implementation into industrial production was successfully achieved.

\section{Acknowledgements}

This work was performed within the German Hardmetal Association (Arbeitskreis Hartmetall), Fachverband Pulvermetallurgie (Hagen, D). The authors would like to thank Mr. Hans Kolaska for his enduring support as well as the representatives and companies supporting his work: Dr. W. Böhlke, Dr. R. Useldinger (Ceratizit S. à r. I., L), Dr. B. Szesny (H.C. Starck GmbH, D), Dr. K. Dreyer, Dr. K. Rödiger. Dr. H. van den Berg (Kennametal Technologies GmbH, D), Dr. T. John, Dr. D. Jung (Saar Hartmetall und Werkzeuge GmbH, D), Dr. R. Schulte (Tigra Hartstoff GmbH, D), Mr. R. Jedamski (Treibacher Industrie AG, A), Mr. A. Wiegand (Tribo Hartstoff $\mathrm{GmbH}, \mathrm{D})$ and Dr. T. Helmer (Walter Hartmetall GmbH, D).

\section{References}

[1] G. Gille, B. Szesny, K. Dreyer, H. van den Berg, J. Schmidt, T. Gestrich, Submicron and ultrafine grained hardmetals for microdrills and metal cutting inserts, Int $\mathrm{J}$ Refract Met $\mathrm{H}$ 20 (2002) 3-22.

[2] K. Choi, N.R. Hwang, D.Y. Kim, Effect of VC addition on microstructural evolution of WCCo alloy: mechanism of grain growth inhibition, Powder Metall 43 (2000) 168-72. 
[3] D.F. Carroll, Sintering and microstructural development in WC/Co-based alloys made with superfine WC powder. Int J Refract Met H 17 (1999) 123-32.

[4] A. Adorjan, W.-D. Schubert, A. Schön, A. Bock, B. Zeiler, WC grain growth during the early stages of sintering, Int J Refract Met H 24 (2006) 365-73.

[5] C.W. Morton, D.J. Wills, K. Stjernberg, The temperature ranges for maximum effectiveness of grain growth inhibitors in WC-Co alloys. Int J Refract Met H 23 (2005) 287-93.

[6] K. Hayashi, Y. Fuke, H. Suzuki, Effects of addition carbides on the grain size of WC-Co alloy. J Jap Soc Powd Powd Metall 19 (1972) 67-71.

[7] M. Kawakami, K. Kitamura, Segregation layers of grain growth inhibitors at WC/WC interfaces in VC-doped submicron-grained WC-Co cemented carbides. Int J Refract Met H 52 (2015) 229-34.

[8] S. Lay, M. Loubradou, S.A.E. Johansson, G. Wahnström, Interface structure in a WCCo alloy co-doped with VC and Cr3C2. J Mater Sci 47 (2012) 1588-93.

[9] M. Kawakami, O. Terada, K. Hayashi, HRTEM microstructure and segregation amount of dopants at WC/Co interfaces in TiC and TaC mono-doped WC-Co submicron-grained hardmetals. J Jap Soc Powd Powd Metall 53 (2006) 166-71.

[10] M. Kawakami, O. Terada, K. Hayashi, Segregation amount of dopants at WC/Co interface in $\mathrm{Cr} 3 \mathrm{C} 2$ and $\mathrm{VC}+\mathrm{Cr} 3 \mathrm{C} 2$-doped WC-Co submicron-grained hardmetals. $16^{\text {th }}$ Plansee Seminar. Reutte, Austria (2005) 653-67.

[11] S. Lay, J. Thibault, S. Hamar-Thibault, Structure and role of the interfacial layers in VCrich WC-Co cermets. Philos Mag 83 (2003) 1175-90.

[12] S. Lay, S. Hamar-Thibault, A. Lackner, Location of VC in VC, Cr3C2 codoped WC-Co cermets by HREM and EELS. Int J Refract Met H 20 (2002) 61-9.

[13] S. Lay, S. Hamar-Thibault, A. Lackner, HREM characterisation of VC in doped WC-Co Cermets. $15^{\text {th }}$ Plansee Seminar. Reutte, Austria (2001) 50-64.

[14] T. Yamamoto, Y. Ikuhara, T. Sakuma, High resolution transmission electron microscopy study in VC-doped WC-Co compound. Sci Technol Adv Mater 1 (2000) 97104.

[15] A. Delanoe, M. Bacia, E. Pauty, S. Lay, C.H. Allibert, Cr-rich layer at the WC/Co interface in Cr-doped WC-Co cermets: segregation or metastable carbide? J Cryst Growth 270 (2004) 219-27.

[16] C. Toufar, W.-D. Schubert, M. Hashiya, Y. Kubo, On the formation of precipitations in highly $(\mathrm{Cr}, \mathrm{V})$-doped cemented carbides. $18^{\text {th }}$ Plansee Seminar. Reutte, Austria (2013)

[17] K. Frisk, A. Markström, Effect of $\mathrm{Cr}$ and $\mathrm{V}$ on phase equilibria in Co-WC based hardmetals. Int J Mater Res 99 (2008) 287-93.

[18] K. Frisk, S. Norgren, J. Zackrisson, A. Markström, B. Jansson, Phase equilibria in cemented carbides based on $\mathrm{C}-\mathrm{Co}-\mathrm{W}$ with $\mathrm{Nb}, \mathrm{Ta}$, Ti and $\mathrm{V}$ additions using thermodynamic calculations. 16th Plansee Seminar. Reutte, Austria (2005) 184-97.

[19] E.G. Obbard, S. Luyckx, S. Hamar-Thibault, C.H. Allibert, Determination of the composition range suitable to the formation of WC- $(\mathrm{V}, \mathrm{W}) \mathrm{C}-\mathrm{x}-\mathrm{Co}$ materials. Int $\mathrm{J}$ Refract Met H 19 (2001) 349-57.

[20] H. Suzuki, K. Tokumoto, Microstructures and mechanical properties of WC-Cr3C2-15\% Co cemented carbide. J Jap Soc Powd Powd Metall 311 (1984) 56-9.

[21] O. Rüdiger, D. Hirschfeld, A. Hoffmann, H. Kolaska, G. Ostermann, J. Willbrand, Composition and properties of the binder metal in cobalt bonded tungsten carbide. Int $\mathrm{J}$ Powd Metall (1971) 29-38.

[22] H. Suzuki, H. Kubota, The influence of binder phase composition on the properties of WC-Co cemented carbides, Planseeber Pulvermet 14 (1966) 96-109.

[23] O. Rüdiger, Das Bindemetall - ein Problem der Hartmetallforschung. Powder Metall Int. 15 (1983) 4-6.

[24] S. Haglund, J. Ågren, W content in Co binder during sintering of WC-Co. Acta Mater 46 (1998) 2801-7.

[25] J. Hinnüber, O. Rüdiger, Die Bedeutung des Kobalt für die Hartmetallindustrie, Kobalt 19 (1963) 56-65. 
[26] A. Markström, B. Sundman, K. Frisk, A revised thermodynamic description of the CoW-C system. J Phase Equilib Diff 26 (2005) 152-60.

[27] P. Zhou, Y. Peng, C. Buchegger, Y. Du, W. Lengauer, Experimental investigation and thermodynamic assessment of the C-Co-Fe-Ni-W system. Int J Refr Met H 54 (2016) 60-69.

[28] W. Lengauer, M. Bohn, R. Hochenauer, L. Lauter, Binder phase analysis for property improvement of WC-Co and WC-TiC-(Ta,Nb)C-Co hardmetals, Proc PM2010 World Congress. Florence, Italy (2010) 621-28.

[29] W. Lengauer, J. Bauer, M. Bohn, H. Wiesenberger, P. Ettmayer, Electron-probe microanalysis of light elements in multiphase diffusion couples. Microchim Acta 126 (1997) 279-88.

[30] M. Brieseck, M. Bohn, W. Lengauer, Diffusion and solubility of Cr in WC. J.Alloys Compd. 489 (2010) 408-414.

[31] J. Garcia, W. Lengauer, Quantitative mass spectrometry of decarburisation and denitridation of cemented carbonitrides during sintering, Mikrochim Acta 136 (2001) 8389.

[32] C. Buchegger, W. Lengauer, J. Bernardi, J. Gruber, T. Ntaflos, F. Kiraly, Diffusion parameters of grain-growth inhibitors in WC-based hardmetals with $\mathrm{Co}, \mathrm{Fe} / \mathrm{Ni}$ and $\mathrm{Fe} / \mathrm{Co} / \mathrm{Ni}$ binder alloys, Int J Refract Met H 49 (2015) 67-74.

[33] C. Buchegger, J. Langlade, W. Lengauer, Interdependencies of grain-growth inhibitor diffusion in WC-Co hardmetals. 18th Plansee Seminar. Reutte, Austria (2013) 1587-97.

[34] M. Brieseck, I. Hünsche, B. Caspers, G. Gille, M. Bohn, W. Lengauer, Diffusion behaviour of the grain-growth inhibitor VC in hardmetals. Defect Diffus Forum 323-325 (2012) 509-14.

[35] M. Brieseck, I. Hünsche, B. Caspers, B. Szesny, G. Gille, W. Lengauer, Optimised sintering and grain-growth inhibition of ultrafine and near-nano hardmetals. Proc EuroPM2009, Copenhagen, Denmark (2009). 
Tables

Tab. 1: Literature data on the solid-state solubility of vanadium and chromium in cobalt binder. Co phase is fcc, the GGI-based free carbide MC in the V-containing samples further contains $\mathrm{Cr}, \mathrm{W}$ and a minor amount of Co. The stoichiometry of in the GGl-based free carbide in $\mathrm{Cr}$ containing samples is $\mathrm{M}_{7} \mathrm{C}_{3}$, where $\mathrm{M}$ is $\mathrm{Cr}$, Co and some minor amount of $\mathrm{W}$ [17].

\begin{tabular}{|c|c|c|c|c|c|c|}
\hline System & Equilibrium & $\mathrm{T}$ & $\begin{array}{c}\mathrm{V} \\
{\left[{ }^{\circ} \mathrm{C}\right]}\end{array}$ & $\begin{array}{c}\mathrm{Cr} \\
{[\mathrm{wt} \%]}\end{array}$ & $\begin{array}{c}\mathrm{W} \\
{[\mathrm{wt} \%]}\end{array}$ & Ref. \\
\hline \multirow{3}{*}{$\begin{array}{c}\text { V-W-C- } \\
\text { Co }\end{array}$} & $\mathrm{Co}+\mathrm{MC}+\mathrm{WC}+$ graphite & 1200 & 1.3 & - & 6.4 & {$[19]$} \\
\cline { 2 - 7 } & 1261 & 1.9 & - & 8.6 & {$[17]$} \\
\cline { 2 - 7 } & Liquid + Co + MC + WC + graphite & 1262 & 4.1 & - & 11.4 & {$[17]$} \\
\cline { 2 - 7 } & $\mathrm{Co}+\mathrm{MC}+\mathrm{WC}+\mathrm{M}_{6} \mathrm{C}$ & 1300 & 4.6 & - & 12.1 & {$[17]$} \\
\hline \multirow{2}{*}{$\begin{array}{c}\text { Cr-W-C- } \\
\text { Co }\end{array}$} & $\mathrm{Co}+\mathrm{M}_{7} \mathrm{C}_{3}+\mathrm{WC}+$ graphite & 1190 & 2.4 & - & 17.9 & {$[19]$} \\
\cline { 2 - 7 } & Liquid $+\mathrm{Co}+\mathrm{M}_{7} \mathrm{C}_{3}+\mathrm{WC}+$ graphite & 1191 & - & 6.9 & 6.2 & {$[17]$} \\
\hline
\end{tabular}

Tab. 2: Composition of M series (WC-Co) model alloys. All values in wt\%. The balance is WC. " $+\mathrm{C}$ " designates the presence of free carbon, "+eta" designates the presence of eta phase in the alloys

\begin{tabular}{|c|c|c|c|c|c|c|c|c|c|c|}
\hline Sample & Carbon & $\mathrm{Cr}_{3} \mathrm{C}_{2}$ & $\mathrm{Mo}_{2} \mathrm{C}$ & $\mathrm{TaC}$ & $\mathrm{VC}$ & $\mathrm{NbC}$ & $\mathrm{ZrC}$ & C & $\mathrm{W}$ & Co \\
\hline \multirow{2}{*}{ M_Cr } & $+\mathrm{C}$ & 7.31 & & & & & & 1.28 & & 63.99 \\
\hline & +eta & 12.37 & & & & & & & 16.96 & 49.47 \\
\hline \multirow{2}{*}{ M_Mo } & $+\mathrm{C}$ & & 9.09 & & & & & 1.26 & & 62.76 \\
\hline & +eta & & 8.96 & & & & & & 2.70 & 61.84 \\
\hline \multirow{2}{*}{ M_Ta } & $+\mathrm{C}$ & & & 11.28 & & & & 0.53 & & 61.73 \\
\hline & +eta & & & 9.99 & & & & & 11.94 & 54.65 \\
\hline \multirow{2}{*}{ M_V } & $+\mathrm{C}$ & & & & 4.93 & & & 0.57 & & 66.15 \\
\hline & +eta & & & & 4.02 & & & & 18.87 & 53.97 \\
\hline \multirow{2}{*}{ M_Nb } & $+\mathrm{C}$ & & & & & 6.47 & & 0.56 & & 65.08 \\
\hline & +eta & & & & & 5.69 & & & 12.51 & 57.26 \\
\hline \multirow{2}{*}{ M_Zr } & $+\mathrm{C}$ & & & & & & 6.51 & 0.56 & & 65.06 \\
\hline & +eta & & & & & & 5.72 & & 12.51 & 57.24 \\
\hline \multirow{2}{*}{ M_NbZr } & $+\mathrm{C}$ & & & & & 6.97 & 6.75 & 0.51 & & 60.03 \\
\hline & +eta & & & & & 7.01 & 6.78 & & 17.24 & 48.27 \\
\hline \multirow{2}{*}{ M_CrV } & $+\mathrm{C}$ & 7.11 & & & 2.78 & & & 1.24 & & 62.20 \\
\hline & +eta & 6.17 & & & 4.83 & & & & 11.81 & 54.03 \\
\hline \multirow{2}{*}{ M_CrTa } & $+\mathrm{C}$ & 6.55 & & 10.47 & & & & 1.15 & & 57.29 \\
\hline & +eta & 11.34 & & 8.29 & & & & & 15.55 & 45.37 \\
\hline \multirow{2}{*}{ M_TaV } & $+\mathrm{C}$ & & & 10.03 & 4.44 & & & 0.51 & & 59.52 \\
\hline & +eta & & & 8.92 & 3.95 & & & & 11.56 & 52.90 \\
\hline \multirow{2}{*}{ M_CrTaV } & $+\mathrm{C}$ & 5.14 & & 5.48 & 2.68 & & & 1.03 & & 59.97 \\
\hline & +eta & 5.88 & & 4.71 & 4.61 & & & & 11.25 & 51.48 \\
\hline
\end{tabular}


Tab. 3: Composition MC series (WC-MC-Co) model alloys. All values in wt\%. "+C" designates the presence of free carbon, "+eta" designates the presence of eta phase in the alloys

\begin{tabular}{|c|c|c|c|c|c|c|c|c|c|c|c|}
\hline Sample & Carbon & WC & $\mathrm{TiC}$ & $\mathrm{TaC}$ & $\mathrm{NbC}$ & TiN & $\mathrm{Cr}_{3} \mathrm{C}_{2}$ & VC & C & W & Co \\
\hline \multirow[b]{2}{*}{ MC } & $+\mathrm{C}$ & 29.51 & 4.10 & 6.15 & 2.05 & & & & & 8.20 & 50.00 \\
\hline & +eta & 30.09 & 4.03 & 6.04 & 2.01 & & & & 0.95 & & 56.87 \\
\hline \multirow{2}{*}{ MC_Cr } & $+\mathrm{C}$ & 27.60 & 3.60 & 5.40 & 1.80 & & 5.60 & & & 8.00 & 48.00 \\
\hline & +eta & 30.00 & 3.91 & 5.87 & 1.96 & & 5.22 & & 0.87 & & 52.17 \\
\hline \multirow{2}{*}{ MC_V } & $+\mathrm{C}$ & 28.63 & 3.73 & 5.60 & 1.87 & & & 2.07 & & 8.30 & 49.79 \\
\hline & +eta & 29.40 & 3.94 & 5.90 & 1.97 & & & 2.31 & 0.93 & & 55.56 \\
\hline \multirow{2}{*}{ MC_N1 } & $+\mathrm{C}$ & 28.48 & 2.59 & 5.55 & 1.85 & 1.11 & & & & 8.63 & 51.79 \\
\hline & +eta & 30.24 & 2.81 & 6.03 & 2.01 & 1.21 & & & 0.95 & & 56.75 \\
\hline \multirow{2}{*}{ MC_N1_Cr } & $+\mathrm{C}$ & 26.81 & 2.55 & 5.46 & 1.82 & 1.09 & 5.66 & & & 8.09 & 48.52 \\
\hline & +eta & 29.25 & 2.64 & 5.66 & 1.89 & 1.13 & 5.32 & & 0.89 & & 53.23 \\
\hline \multirow{2}{*}{ MC_N1_V } & $+\mathrm{C}$ & 27.89 & 2.52 & 5.39 & 1.80 & 1.08 & & 2.11 & & 8.46 & 50.75 \\
\hline & +eta & 28.55 & 2.79 & 5.97 & 1.99 & 1.19 & & 2.34 & 0.94 & & 56.22 \\
\hline \multirow{2}{*}{ MC_N2 } & $+\mathrm{C}$ & 27.86 & 1.94 & 5.83 & 1.94 & 1.94 & & & & 8.64 & 51.84 \\
\hline & +eta & 29.55 & 2.13 & 6.38 & 2.13 & 2.13 & & & 0.95 & & 56.74 \\
\hline \multirow{2}{*}{ MC_N2_Cr } & $+\mathrm{C}$ & 26.27 & 1.83 & 5.50 & 1.83 & 1.83 & 5.70 & & & 8.15 & 48.88 \\
\hline & +eta & 28.73 & 2.00 & 5.68 & 1.89 & 2.00 & 5.35 & & 0.89 & & 53.45 \\
\hline \multirow{2}{*}{ MC_N2_V } & $+\mathrm{C}$ & 27.27 & 1.90 & 5.71 & 1.90 & 1.90 & & 2.11 & & 8.46 & 50.74 \\
\hline & +eta & 29.52 & 2.06 & 6.18 & 2.06 & 2.06 & & 2.29 & 0.92 & & 54.92 \\
\hline
\end{tabular}

Tab. 4: Composition of hardmetals. All values in wt\%.

\begin{tabular}{|c|c|c|c|c|c|c|}
\hline Sample & $\mathrm{WC}$ & $\mathrm{Cr}_{3} \mathrm{C}_{2}$ & $\mathrm{Mo}_{2} \mathrm{C}$ & $\mathrm{TaC}$ & $\mathrm{VC}$ & $\mathrm{Co}$ \\
\hline $\mathrm{HCr}$ & 89.06 & 0.94 & & & & 10.0 \\
\hline $\mathrm{HMo}$ & 89.49 & & 0.51 & & & 10.0 \\
\hline $\mathrm{HTa}$ & 89.90 & & & 0.10 & & 10.0 \\
\hline $\mathrm{HV}$ & 89.83 & & & & 0.17 & 10.0 \\
\hline $\mathrm{HCrV}$ & 89.25 & 0.63 & & & 0.12 & 10.0 \\
\hline $\mathrm{HCrTa}$ & 88.98 & 0.92 & & 0.10 & & 10.0 \\
\hline $\mathrm{HVTa}$ & 89.73 & & & 0.10 & 0.17 & 10.0 \\
\hline $\mathrm{HCrVTa}$ & 89.22 & 0.58 & & 0.10 & 0.10 & 10.0 \\
\hline
\end{tabular}


Tab. 5: Composition of the of binder phase of M-type WC-Co model alloys after cool-down.

\begin{tabular}{|c|c|c|c|c|c|c|c|c|c|c|}
\hline \multirow{2}{*}{ Sample } & \multirow{2}{*}{ Carbon } & \multicolumn{9}{|c|}{ Composition [wt\%] } \\
\hline & & $\mathrm{Cr}$ & Mo & $\mathrm{Ta}$ & V & $\mathrm{Nb}$ & $\mathrm{Zr}$ & $\mathrm{C}$ & W & Co \\
\hline \multirow{2}{*}{$\mathrm{MCr}$} & $+\mathrm{C}$ & 5.7 & & & & & & 0.2 & 7.2 & 86.9 \\
\hline & +eta & 10.5 & & & & & & 0.2 & 13.1 & 76.3 \\
\hline \multirow{2}{*}{ MMo } & $+\mathrm{C}$ & & 4.8 & & & & & 0.7 & 3.1 & 91.4 \\
\hline & +eta & & 4.8 & & & & & 0.6 & 13.7 & 81.0 \\
\hline \multirow{2}{*}{ MTa } & $+\mathrm{C}$ & & & $<$ d.I & & & & $\overline{0.1}$ & 5.4 & 94.5 \\
\hline & +eta & & & 2.1 & & & & 0.5 & 22.1 & 75.3 \\
\hline \multirow{2}{*}{ MV } & $+\mathrm{C}$ & & & & 1.0 & & & 0.6 & 8.2 & 90.3 \\
\hline & +eta & & & & 1.7 & & & 0.3 & 18.0 & 80.0 \\
\hline \multirow{2}{*}{ MNb } & $+\mathrm{C}$ & & & & & $<$ d.I. & & 0.3 & 6.6 & 93.1 \\
\hline & +eta & & & & & 0.1 & & 0.4 & 22.6 & 76.9 \\
\hline \multirow{2}{*}{$\mathrm{MZr}$} & $+\mathrm{C}$ & & & & & & $<$ d.I & 0.4 & 6.1 & 93.5 \\
\hline & +eta & & & & & & 0.4 & 0.4 & 16.3 & 82.9 \\
\hline \multirow{2}{*}{ MNbZr } & $+\mathrm{C}$ & & & & & 0.2 & 0.2 & 0.7 & 5.3 & 93.8 \\
\hline & +eta & & & & & 0.1 & 0.1 & 0.4 & 22.8 & 76.5 \\
\hline \multirow{2}{*}{ MCrV } & $+\mathrm{C}$ & 5.4 & & & 0.8 & & & 0.5 & 7.3 & 86.0 \\
\hline & +eta & 5.5 & & & 1.1 & & & 0.8 & 14.1 & 78.6 \\
\hline \multirow{2}{*}{ MCrTa } & $+\mathrm{C}$ & 6.6 & & $<$ d.I. & & & & $<$ d.I. & 5.5 & 87.9 \\
\hline & +eta & 9.4 & & 0.3 & & & & $<$ d.I. & 11.6 & 78.7 \\
\hline \multirow{2}{*}{ MTaV } & $+\mathrm{C}$ & & & $<$ d.I. & 1.0 & & & $<$ d.I. & 8.5 & 90.5 \\
\hline & +eta & & & $<$ d.I. & 1.8 & & & $<$ d.I. & 19.1 & 79.1 \\
\hline \multirow{2}{*}{ MCrTaV } & $+\mathrm{C}$ & 4.9 & & $<$ d.I. & 0.7 & & & $<$ d.I. & 8.3 & 86.2 \\
\hline & +eta & 5.2 & & $<$ d.I. & 0.9 & & & $<$ d.I. & 14.7 & 79.1 \\
\hline
\end{tabular}

Tab. 6: Composition of the binder phase of M-type WC-Co model alloys after 168h equilibration at $1000^{\circ} \mathrm{C}$.

\begin{tabular}{|c|c|c|c|c|c|c|c|c|c|c|}
\hline \multirow{2}{*}{ Sample } & \multirow{2}{*}{ Carbon } & \multicolumn{9}{|c|}{ Composition [wt\%] } \\
\hline & & $\mathrm{Cr}$ & Mo & $\mathrm{Ta}$ & $\mathrm{V}$ & $\mathrm{Nb}$ & $\mathrm{Zr}$ & $\mathrm{C}$ & W & Co \\
\hline \multirow{2}{*}{$\mathrm{MCr}$} & $+\mathrm{C}$ & $\overline{5.4}$ & & & & & & $\overline{0.4}$ & 3.1 & 91.1 \\
\hline & +eta & 9.8 & & & & & & 0.3 & 11.5 & 78.4 \\
\hline \multirow{2}{*}{ MMo } & $+\mathrm{C}$ & & 4.6 & & & & & 0.5 & 3.4 & 91.5 \\
\hline & +eta & & 3.9 & & & & & 0.3 & 8.6 & 87.1 \\
\hline \multirow{2}{*}{ MTa } & $+\mathrm{C}$ & & & $<$ d.I. & & & & 0.3 & 3.1 & 96.6 \\
\hline & +eta & & & 1.9 & & & & 0.2 & 19.2 & 78.8 \\
\hline \multirow{2}{*}{ MV } & $+\mathrm{C}$ & & & & 1.1 & & & 0.4 & 4.0 & 94.4 \\
\hline & +eta & & & & 2.3 & & & 0.3 & 16.6 & 80.9 \\
\hline \multirow{2}{*}{$\mathrm{MNb}$} & $+\mathrm{C}$ & & & & & 0.2 & & 0.2 & 2.8 & 96.9 \\
\hline & +eta & & & & & n.a. & & n.a. & n.a. & n.a. \\
\hline \multirow{2}{*}{$\mathrm{MZr}$} & $+\mathrm{C}$ & & & & & & n.a. & n.a. & n.a. & n.a. \\
\hline & +eta & & & & & & 0.3 & 0.6 & 9.5 & 89.6 \\
\hline \multirow{2}{*}{ MNbZr } & $+\mathrm{C}$ & & & & & $<$ d.I. & $<$ d.I. & 0.6 & 6.4 & 92.8 \\
\hline & +eta & & & & & n.a. & n.a. & n.a. & n.a. & n.a. \\
\hline \multirow{2}{*}{ MCrV } & $+\mathrm{C}$ & 4.9 & & & 0.7 & & & 0.2 & 4.3 & 89.9 \\
\hline & +eta & 6.2 & & & 1.3 & & & 0.1 & 10.0 & 82.3 \\
\hline \multirow{2}{*}{ MCrTa } & $+\mathrm{C}$ & 5.6 & & $<$ d.I. & & & & $<$ d.I. & 3.5 & 91.1 \\
\hline & +eta & 9.6 & & $<$ d.I. & & & & $<$ d.I. & 9.8 & 80.6 \\
\hline \multirow{2}{*}{ MTaV } & $+\mathrm{C}$ & & & $<$ d.I. & 1.4 & & & $<$ d.I. & 7.1 & 91.5 \\
\hline & +eta & & & $<$ d.I. & 2.1 & & & $<$ d.I. & 17.4 & 80.3 \\
\hline \multirow{2}{*}{ MCrTaV } & $+\mathrm{C}$ & 4.8 & & $<$ d.I. & 0.7 & & & $<$ d.I. & 4.6 & 89.9 \\
\hline & +eta & 5.8 & & $<$ d.I. & 1.5 & & & $<$ d.I. & 10.5 & 82.1 \\
\hline
\end{tabular}


Tab. 7: Composition of eta-phase in model alloys with various dopants. (e) marks equilibrated samples. ${ }^{*}$ Phase is not saturated in chromium; ${ }^{* *}$ Carbon analysis is only semi-quantitative. All values in wt\%.

\begin{tabular}{|c|c|c|c|c|}
\hline & \multicolumn{4}{|c|}{$\left(\mathrm{Co}_{\mathrm{u}} \mathrm{W}_{\mathrm{v}} \mathrm{Me}_{\mathrm{w}}\right)_{6} \mathrm{C}_{\mathrm{x}}$} \\
\hline Sample & u (Co) & $\mathrm{v}(\mathrm{W})$ & w (Me) & $x(C)^{* *}$ \\
\hline $\mathrm{MCr}$ & 3.2 & 2.4 & $0.4^{*}$ & 0.8 \\
\hline $\operatorname{MCr}(\mathrm{e})$ & 2.9 & 2.7 & $0.5^{*}$ & 0.8 \\
\hline MMo & 3.1 & 1.9 & 1.0 & 1.2 \\
\hline MMo (e) & 3.2 & 1.8 & 1.0 & 1.1 \\
\hline MTa (e) & 3.1 & 2.7 & 0.2 & 0.6 \\
\hline MV (e) & 3.0 & 2.6 & 0.4 & 1.0 \\
\hline $\mathrm{MNb}(\mathrm{e})$ & 3.0 & 2.8 & 0.1 & 0.6 \\
\hline MCrV & 2.9 & 2.3 & $0.4 \mathrm{Cr}$ & 0.7 \\
\hline \multirow{2}{*}{$\operatorname{MCrTa}(\mathrm{e})$} & \multirow{2}{*}{3.0} & \multirow{2}{*}{2.5} & $0.4 \mathrm{~V}$ & \multirow{2}{*}{0.8} \\
\hline & & & $0.1 \mathrm{Ta}$ & \\
\hline \multirow{3}{*}{ MCrVTa } & \multirow{3}{*}{3.0} & \multirow{3}{*}{2.5} & $0.6 \mathrm{Cr}^{*}$ & \multirow{3}{*}{0.8} \\
\hline & & & $0.2 \mathrm{~V}$ & \\
\hline & & & $0.2 \mathrm{Ta}$ & \\
\hline \multirow{3}{*}{$\begin{array}{c}\text { MCrVTa } \\
\text { (e) }\end{array}$} & \multirow{3}{*}{3.2} & \multirow{3}{*}{2.5} & $0.2 \mathrm{Cr}^{*}$ & \multirow{3}{*}{0.9} \\
\hline & & & $0.2 \mathrm{~V}$ & \\
\hline & & & $0.1 \mathrm{Ta}$ & \\
\hline
\end{tabular}

Tab. 8: Solubilities of $\mathrm{Cr}, \mathrm{V}$ and $\mathrm{W}$ in the binder phase of the MC-type WC-MC-Co model alloys. Carbon analysis is semi-quantitative. All values in wt\%.

\begin{tabular}{|c|c|c|c|c|c|c|c|c|c|}
\hline \multirow{2}{*}{ Sample } & \multirow{2}{*}{ Carbon } & \multicolumn{4}{|c|}{ Sintered in Ar } & \multicolumn{4}{|c|}{ Sintered in $\mathrm{N}_{2}$} \\
\hline & & W & $\mathrm{Cr}$ & $\mathrm{V}$ & C & W & $\mathrm{Cr}$ & $\mathrm{V}$ & C \\
\hline \multirow{2}{*}{$\mathrm{MC}$} & $+\mathrm{C}$ & 6.3 & - & - & 0.9 & 8.2 & - & - & 0.6 \\
\hline & +eta & 20.3 & - & - & 1.0 & 20.9 & - & - & 1.0 \\
\hline \multirow{2}{*}{ MC_Cr } & $+\mathrm{C}$ & 4.2 & 6.1 & - & 1.2 & 4.2 & 6.0 & - & 1.0 \\
\hline & +eta & 9.8 & 6.8 & - & 1.4 & 10.2 & 7.2 & - & 0.9 \\
\hline \multirow{2}{*}{ MC_V } & $+\mathrm{C}$ & 5.4 & - & 0.6 & 0.9 & 4.5 & - & 0.7 & 0.8 \\
\hline & +eta & 17.0 & - & 1.3 & 0.9 & 15.8 & - & 1.2 & 0.7 \\
\hline \multirow{2}{*}{ MC_N1 } & $+\mathrm{C}$ & 9.3 & - & - & 0.7 & 7.2 & - & - & 0.8 \\
\hline & +eta & 19.6 & - & - & 0.8 & 19.3 & - & - & 0.8 \\
\hline \multirow{2}{*}{ MC_Cr_N1 } & $+\mathrm{C}$ & 5.1 & 5.9 & - & 1.1 & 4.6 & 6.1 & - & 1.0 \\
\hline & +eta & 9.9 & 7.7 & - & 1.0 & 9.9 & 6.9 & - & 1.0 \\
\hline \multirow{2}{*}{ MC_V_N1 } & $+\mathrm{C}$ & 4.2 & - & 0.7 & 0.9 & 5.1 & - & 0.8 & 0.8 \\
\hline & +eta & 17.0 & - & 1.3 & 0.7 & 15.5 & - & 1.2 & 0.8 \\
\hline \multirow{2}{*}{ MC_N2 } & $+\mathrm{C}$ & 4.5 & - & - & 1.0 & 6.2 & - & - & 1.2 \\
\hline & +eta & 20.3 & - & - & 0.7 & 20.0 & - & - & 1.0 \\
\hline \multirow{2}{*}{ MC_Cr_N2 } & $+\mathrm{C}$ & 4.8 & 6.3 & - & 0.7 & 3.9 & 5.6 & - & $\overline{1.4}$ \\
\hline & +eta & 9.9 & 7.1 & - & 1.1 & 10.1 & 6.3 & - & 1.4 \\
\hline \multirow{2}{*}{ MC_V_N2 } & $+\mathrm{C}$ & 7.6 & - & 1.0 & 0.8 & 6.2 & - & 0.9 & 1.0 \\
\hline & +eta & 17.5 & - & 1.7 & 0.8 & 15.2 & - & 1.5 & 1.1 \\
\hline
\end{tabular}


Tab 9: Composition of the cubic phase in MC model alloys. All values in at\%.

\begin{tabular}{|c|c|c|c|c|c|c|c|c|c|}
\hline Sample & Carbon & $\mathrm{Ti}$ & $\mathrm{Ta}$ & $\mathrm{Nb}$ & $\mathrm{Cr}$ & $\mathrm{V}$ & $\mathrm{C}$ & $\mathrm{N}$ & $\mathrm{W}$ \\
\hline \multirow{2}{*}{$\mathrm{MC}$} & $+\mathrm{C}$ & 22.6 & 10.0 & 6.0 & - & - & 50.0 & - & 11.3 \\
\cline { 2 - 10 } & + eta & 22.1 & 9.2 & 5.6 & - & - & 49.5 & - & 13.4 \\
\hline \multirow{2}{*}{$\mathrm{MC} \_\mathrm{Cr}$} & $+\mathrm{C}$ & 21.8 & 9.4 & 5.8 & 2.0 & - & 49.6 & - & 11.4 \\
\cline { 2 - 10 } & + eta & 19.3 & 8.3 & 5.0 & 2.3 & - & 48.9 & - & 16.3 \\
\hline \multirow{2}{*}{ MC_V } & $+\mathrm{C}$ & 21.9 & 9.8 & 5.9 & - & 1.6 & 49.6 & - & 11.2 \\
\cline { 2 - 10 } & + eta & 21.1 & 8.4 & 5.5 & - & 1.4 & 49.0 & - & 14.6 \\
\hline \multirow{2}{*}{ MC_N1 } & $+\mathrm{C}$ & 24.1 & 10.5 & 6.6 & - & - & 48.8 & - & 10.1 \\
\cline { 2 - 10 } & + eta & 23.8 & 10.0 & 6.2 & - & - & 47.8 & 1.7 & 10.4 \\
\hline \multirow{2}{*}{ MC_Cr_N1 } & $+\mathrm{C}$ & 23.4 & 9.9 & 6.1 & 1.9 & - & 48.9 & - & 9.7 \\
\cline { 2 - 10 } & + eta & 22.3 & 9.5 & 5.7 & 2.2 & - & 48.0 & 1.3 & 11.1 \\
\hline \multirow{2}{*}{ MC_V_N1 } & $+\mathrm{C}$ & 21.9 & 9.2 & 5.6 & - & 4.9 & 47.8 & 0.8 & 9.7 \\
\cline { 2 - 10 } & + eta & 20.7 & 8.1 & 5.0 & - & 6.0 & 45.6 & 1.8 & 12.8 \\
\hline
\end{tabular}

Tab.10: Mechanical and magnetic properties of the low-C hardmetals with optimised GGI content.

\begin{tabular}{|c|c|c|c|c|c|c|c|}
\hline Sample & $\begin{array}{c}\text { Porosity(ISO } \\
\text { ) }\end{array}$ & $\begin{array}{c}\text { TRS } \\
{\left[\mathrm{N} / \mathrm{mm}^{2}\right.} \\
]\end{array}$ & $\begin{array}{c}\text { Weibull- } \\
\text { paramete } \\
r\end{array}$ & $\begin{array}{c}\mathrm{HV} 30 \\
{\left[\mathrm{~kg} / \mathrm{mm}^{2}\right]}\end{array}$ & $\begin{array}{c}\mathrm{K}_{\mathrm{Ic}} \\
{\left[\mathrm{MPa} \cdot \mathrm{m}^{0.5}\right.} \\
]\end{array}$ & $\begin{array}{l}4 \pi \sigma \\
{[\%]}\end{array}$ & $\begin{array}{c}\mathrm{Hc} \\
{[\mathrm{kA} / \mathrm{m}]}\end{array}$ \\
\hline $\mathrm{HCr}$ & $\begin{array}{c}\mathrm{A} 00 \mathrm{~B} 00 \\
\mathrm{C} 00\end{array}$ & 4.5 & 43 & 1670 & 10.6 & 80.8 & 20.5 \\
\hline HMo & $\begin{array}{c}\mathrm{A} 00 \mathrm{~B} 00 \\
\mathrm{C} 00\end{array}$ & 4.1 & 33 & 1560 & 10.9 & 81.7 & 17.1 \\
\hline HTa & $\begin{array}{c}\mathrm{A} 00 \mathrm{~B} 00 \\
\mathrm{C} 00\end{array}$ & 3.4 & 31 & 1550 & 11.1 & 81.2 & 16.7 \\
\hline $\mathrm{HV}$ & $\begin{array}{c}\mathrm{A} 00 \mathrm{~B} 00 \\
\mathrm{C} 00\end{array}$ & 4.4 & 49 & 1660 & 10.2 & 79.7 & 20.4 \\
\hline $\mathrm{HCrV}$ & $\begin{array}{c}\mathrm{A} 00 \mathrm{~B} 00 \\
\mathrm{C} 00\end{array}$ & 4.6 & 39 & 1680 & 10.1 & 77.0 & 21.6 \\
\hline HCrTa & $\begin{array}{c}\mathrm{A} 00 \mathrm{~B} 00 \\
\mathrm{C} 00\end{array}$ & 4.7 & 27 & 1690 & 10.2 & 77.5 & 21.3 \\
\hline HTaV & $\begin{array}{c}\mathrm{A} 00 \mathrm{~B} 00 \\
\mathrm{C} 00\end{array}$ & 4.7 & 35 & 1660 & 9.5 & 79.2 & 24.4 \\
\hline HCrVTa & $\begin{array}{c}\mathrm{A} 00 \mathrm{~B} 00 \\
\mathrm{C} 00\end{array}$ & 4.7 & 59 & 1670 & 9.9 & 78.2 & 22.2 \\
\hline
\end{tabular}


Figures

Fig.1: LOM micrographs of series M model alloys for WDS-EPMA analysis, Murakami-etched for 5s. Top image of each sample:WC+fcc-Co+free_GGI_carbides+eta; bottom image of each sample: WC+fcc-Co+free_GGI_carbides+graphite. The free GGI-based carbides are designated as $M_{x} C_{y}$ because these phases have different stoichiometry ranging from $M_{7} C_{3}$ to $\mathrm{MC}_{1-\mathrm{x}}$ (around 50 at\%C) and a varying metal composition $\mathrm{M}$, compare [17].
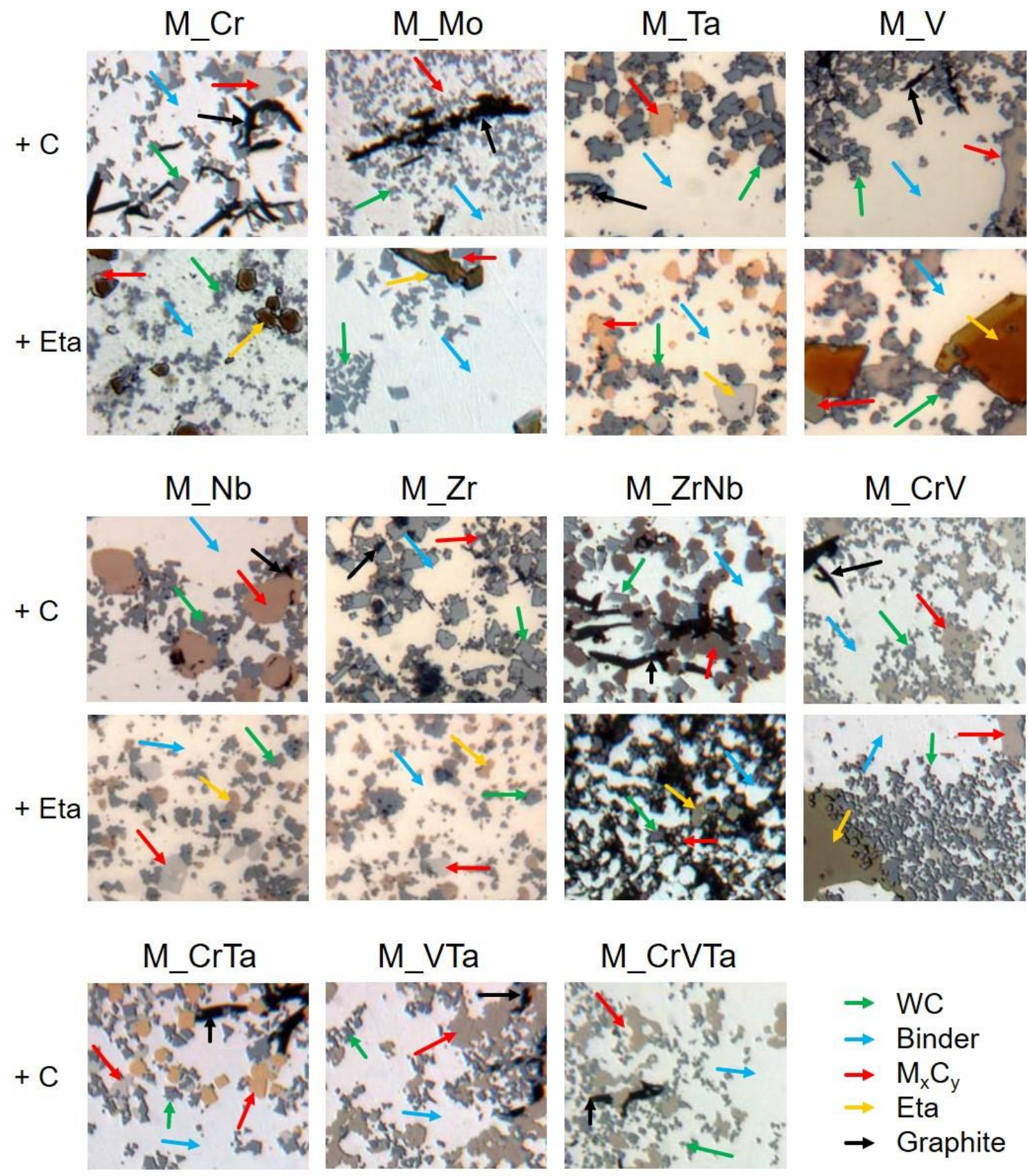

\section{M_CrVTa}

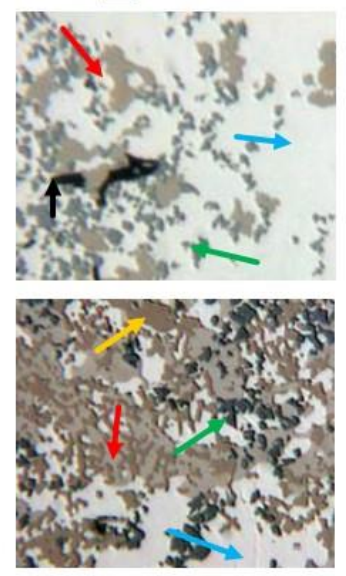

$$
\begin{aligned}
& \rightarrow \text { WC } \\
& \rightarrow \text { Binder } \\
& \rightarrow \mathrm{M}_{\mathrm{x}} \mathrm{C}_{\mathrm{y}} \\
& \rightarrow \text { Eta } \\
& \rightarrow \text { Graphite }
\end{aligned}
$$
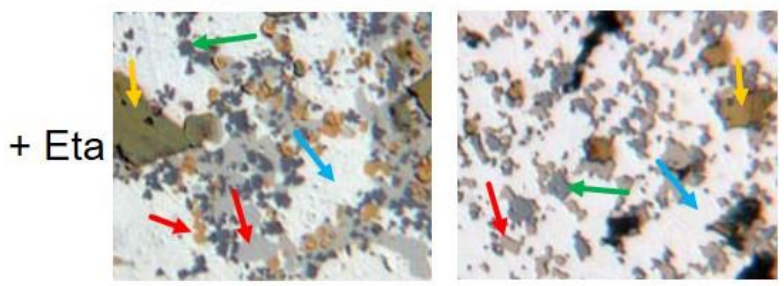
Fig. 2: LOM micrographs of series MC model alloys for WDS-EPMA analysis, Murakamietched for 5s. Top image of each sample: WC+fcc-Co+MC+free_GGl_carbides+eta; bottom image of each sample: WC+fcc-Co+MC+free_GGI_carbides+graphite.
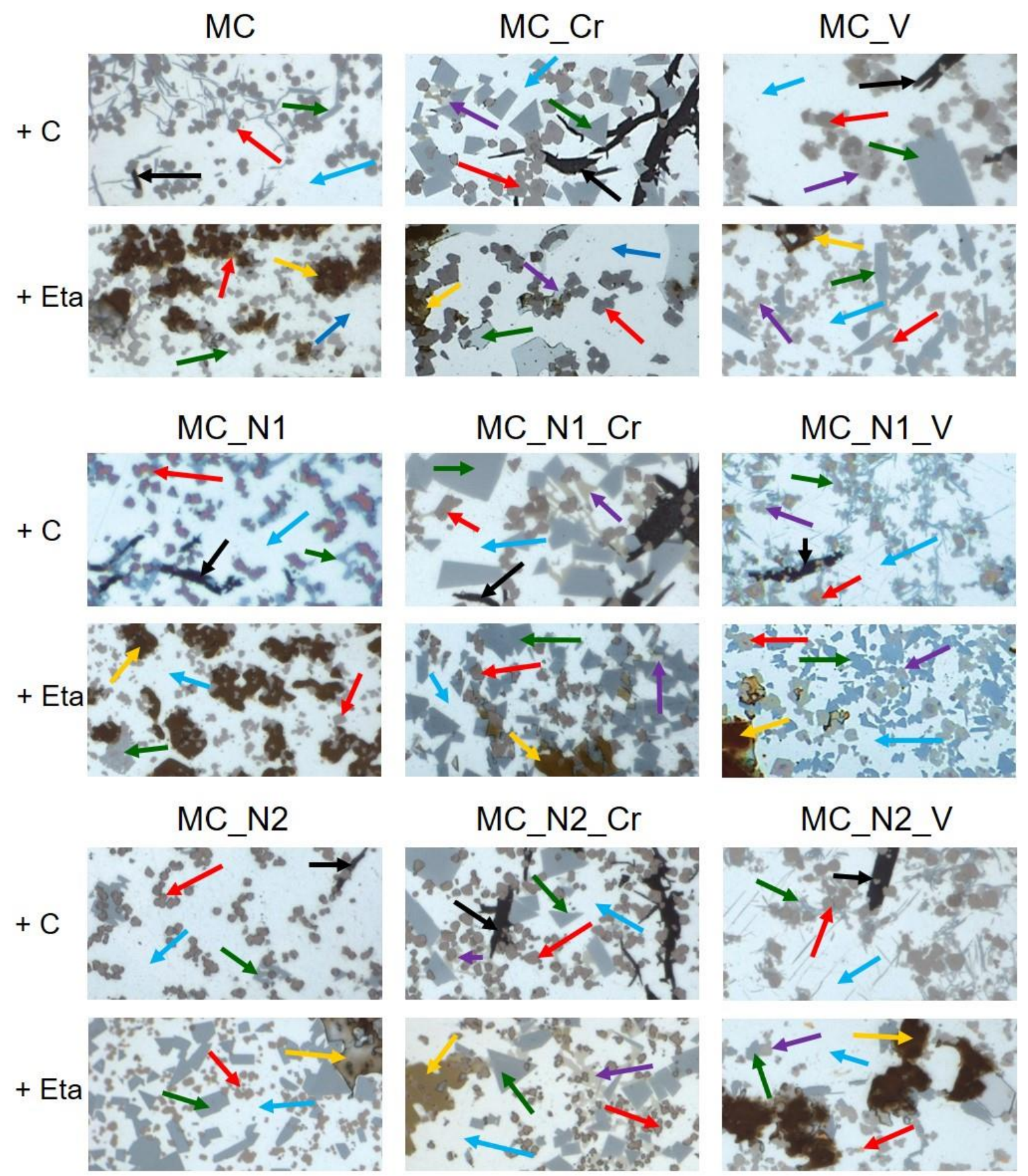

$$
\begin{array}{lll}
\rightarrow \text { WC } & \rightarrow \text { Eta } & \rightarrow \mathrm{MC}, \mathrm{Ti} / \mathrm{Ta} / \mathrm{Nb} \text {-based } \\
\rightarrow \text { Binder } & \rightarrow \text { Graphite } \rightarrow \mathrm{MC}, \mathrm{Cr} / \mathrm{V} \text {-based }
\end{array}
$$

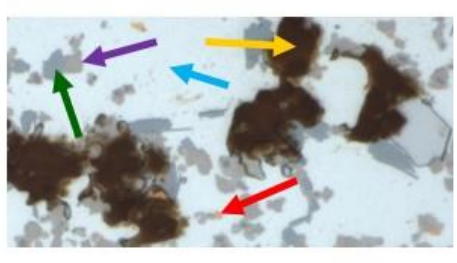

$\underline{20 \mu \mathrm{m}}$ 
Fig. 3: SEM microstructure (SE image) of a $(\mathrm{Cr}+\mathrm{V}+\mathrm{Ta})$-triple-doped hardmetal with optimised doping amount with and low $\mathrm{C}$ potential.

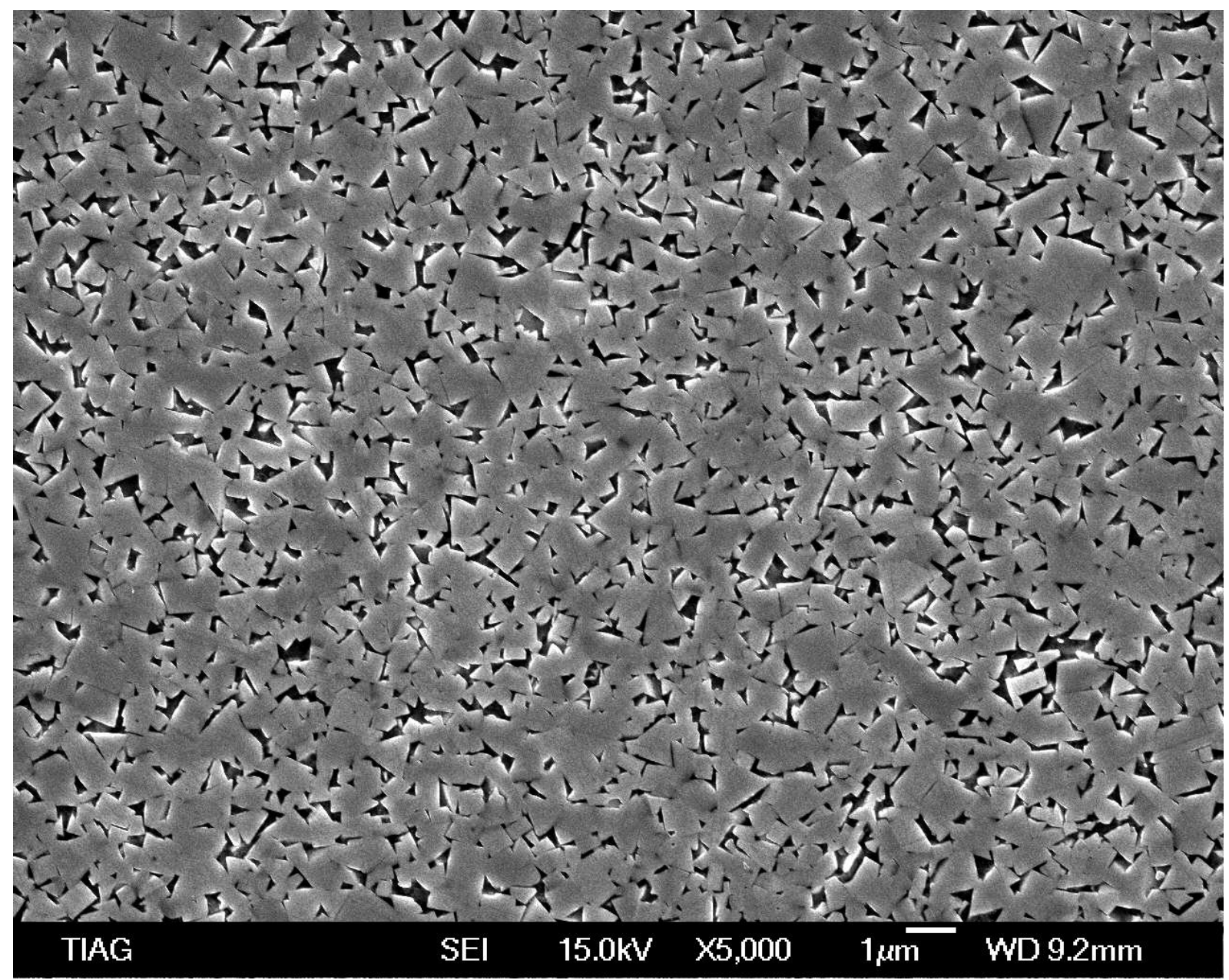

Fig. 4: Weibull plot of hardmetals with optimised inhibitor concentrations and at low $\mathrm{C}$ potential.

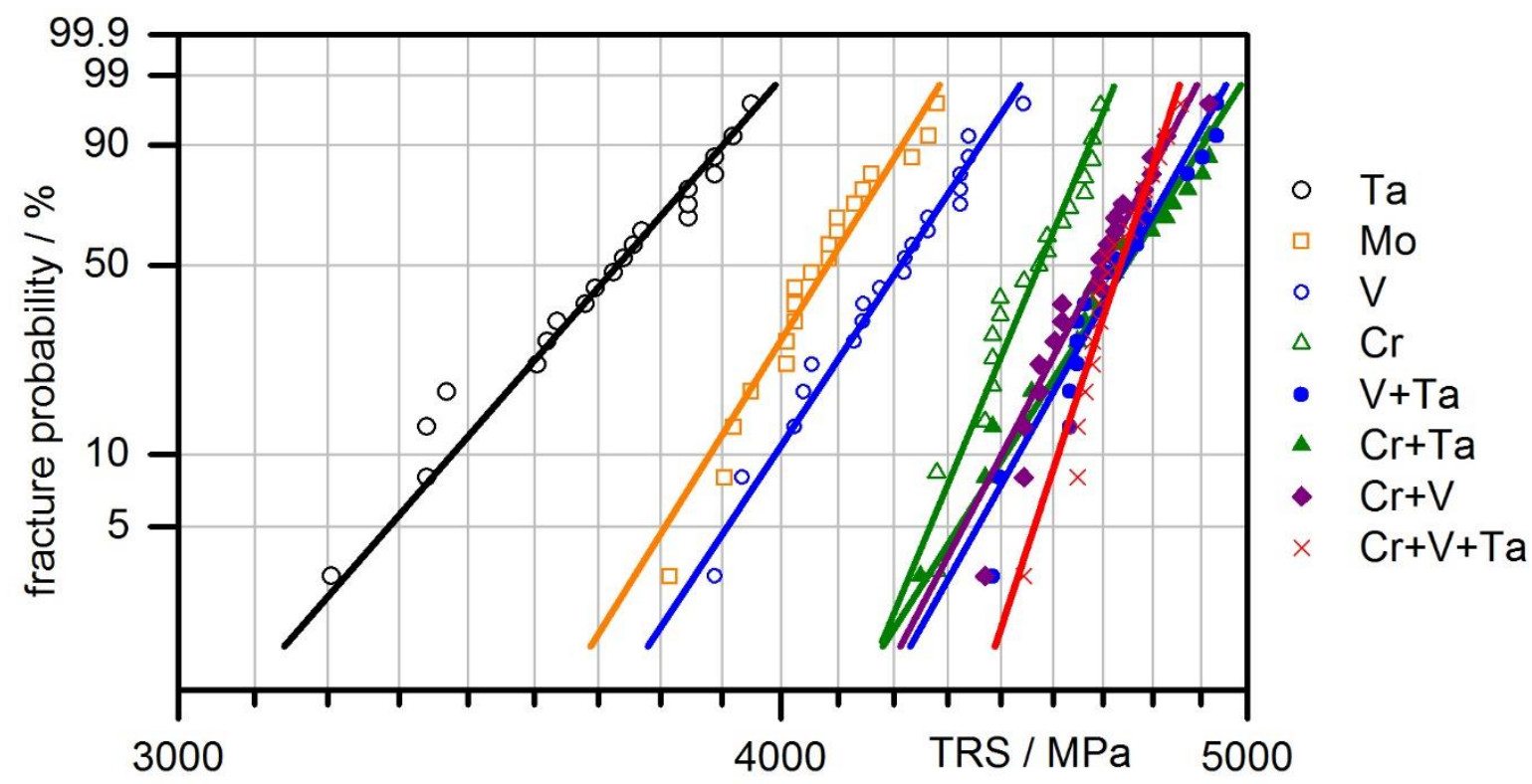


